\title{
Peter B. Dews and Pharmacological Studies on Behavior
}

\author{
James E. Barrett and Jack Bergman \\ Department of Pharmacology and Physiology, Drexel University College of Medicine, Philadelphia, Pennsylvania (J.E.B.); \\ and Department of Psychiatry, Harvard Medical School, Boston, Massachusetts (J.B.)
}

Received March 20, 2008; accepted June 10, 2008

\begin{abstract}
The publications by Peter B. Dews of a series of five articles entitled "Studies on Behavior", beginning in 1955 and ending in 1959, were contributions of extraordinary significance in laying a foundation for the emergence of the discipline of behavioral pharmacology. The series of articles were rigorous in their approach, dramatic in terms of the results, and provocative in their implications. Published at the near half-century mark of
\end{abstract}

the founding of the American Society for Pharmacological and Experimental Therapeutics, it is appropriate to now provide a Centennial Perspective on the impact of these studies over 50 years following their publication and to comment on the way in which they helped to influence the directions in which this discipline has evolved.
Peter B. Dews published the first of a series of five articles in the Journal of Pharmacology and Experimental Therapeutics (JPET) entitled "Studies on Behavior" in 1955 (Dews, 1955a). Before the appearance of these articles, there were rudimentary signs that the effects of drugs could be meaningfully studied using behavior; however, the systematic examination of the behavioral effects of drugs was largely quiescent and had not yet been recognized as a legitimate field of inquiry. At the time of their appearance, approximately midway through the centennial of the founding of American Society for Pharmacology and Experimental Therapeutics (ASPET), these articles were quickly recognized as scientific landmarks within pharmacology. Over the 50 years since their initial appearance, the series of articles by Dews has provided a fundamental cornerstone for the foundation and emergence of behavioral pharmacology. Since that time, behavioral pharmacology has become a widely recognized scientific endeavor within the general scope of pharmacology, with broad reaches also into neuroscience, drug discovery, and toxicology. The publication of these articles by Dews was instrumental in generating a framework for assessing the behavioral effects of drugs, opened new avenues of inquiry, postulated certain principles that spawned vigorous research activities, and provided the first glimpse of the enormously influential role of the environ-

Article, publication date, and citation information can be found at http://jpet.aspetjournals.org.

doi:10.1124/jpet.108.139261. ment in determining the behavioral effects of drugs. This Centennial Perspective documents the key findings and implications of Dews' research starting with the first of the five articles in the JPET and the subsequent impact of this series of articles on the development of the field of behavioral pharmacology.

\section{Historical Background}

A major reason that the analysis of the behavioral effects of drugs in experimental animals was somewhat dormant before the publication of this research was, in Dews' view, that it was "hampered by a paucity of objective, quantitative methods of study" (Dews, 1955a). He acknowledged that the techniques developed by B. F. Skinner and colleagues (Fig. 1) provided an operational approach to objectively and quantifiably study behavior and cited some early work conducted by Skinner and Heron (1937) and Wentink (1938) and some preliminary work by Hill et al. (1954), all of which used rats as subjects and the "Skinner box" as an experimental apparatus to examine the effects of various drugs. However, this initial work was not continued in any systematic manner, perhaps because, with the exception of Wikler (Hill et al., 1954), who was a psychiatrist and who was to be instrumental in research on addictive disorders and drug abuse, these individuals were psychologists by training and interested mainly in nonpharmacological features of the behavioral ef- 


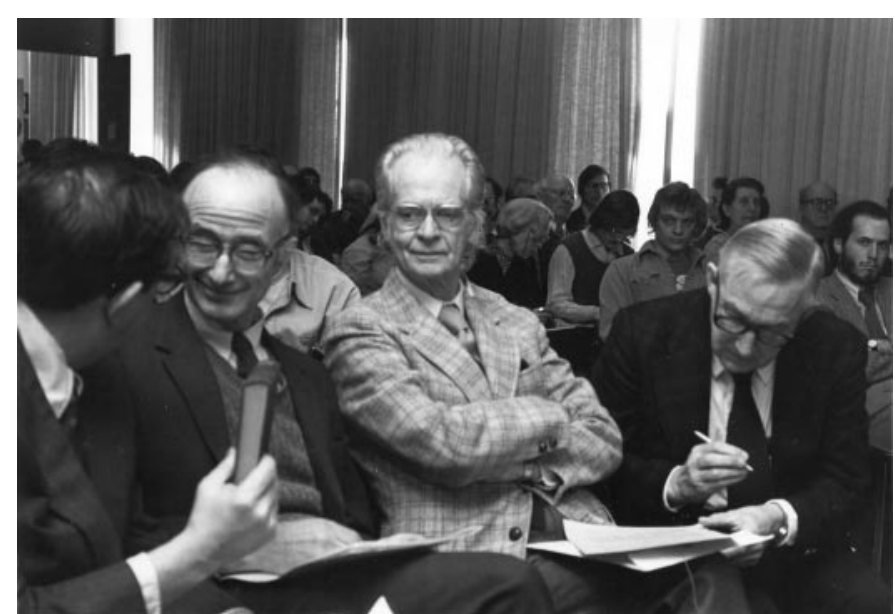

Fig. 1. J. R. Pappenheimer (left), B. F. Skinner (center), and P. B. Dews (right).

fects of drugs. The enormous appeal to Dews of the "strictly operational approach" and the techniques developed by Skinner and colleagues was that the animal was confronted with a device that it could operate; the "response" of the animal was defined as such an operation. The animal was suitably rewarded for responding intermittently; i.e., not every response needed to be rewarded. The rate of response at different times depended upon the contingencies that determine which response will be rewarded. These contingencies can be specified, and responses automatically recorded, so the methods were both objective and quantitative (Dews, 1955a).

At approximately the same time that Dews was beginning to systematically study the behavioral effects of drugs, the study of schedules of reinforcement was being heavily investigated by Skinner and students (Ferster, 1953; Lattal, 2002). The enormous degree of control over behavior exerted by schedules of reinforcement was astounding, and it is clear that Dews was both enamored and influenced by the dynamic range, the orderliness and stability of behavior, the species and response generality, and the sensitivity of schedule-controlled behavior to pharmacological manipulation. In short, these features permitted an appropriate analysis of the behavioral effects of drugs that allowed behavioral research to be more readily incorporated into the established discipline of pharmacology. The groundbreaking aspect of the initial article in JPET (Dews, 1955a) is perhaps best expressed by the following statement taken from that article:

"To show promise of usefulness for the analysis of behavioral effects of drugs, a method should enable a behavioral effect to be detected and measured following doses insufficient to cause gross disturbances of the animal. The principal object of the present communication is to present the Skinner box technique as a method of potential usefulness to pharmacologists and to give evidence that the above requirement is met".

\section{Studies on Behavior. I. Differential Sensitivity to Pentobarbital of Pecking Performance in Pigeons Depending on the Schedule of Reward}

The initial article in JPET (Dews, 1955a) was unique not only in the use of schedules of reinforcement to evaluate drug effects but also in the species selected for study-the pigeon. Dews incorporated the apparatus, techniques, and methods for studying pigeon's key pecking behavior from the research conducted in Skinner's laboratory at Harvard Medical School (see Fig. 2). Although the use of the pigeon may seem to be somewhat of an anomaly in this context, it has turned out that the pigeon offered several distinct advantages for the study of drug effects. Dews subsequently wrote quite elegantly about the choice of the pigeon for these and other pharmacological studies (Dews, 1956). The pigeons, with restrictions on food imposed during the experiment, were trained to peck a translucent Plexiglas key using the method of successive approximations with grain presentation as food reinforcement (Ferster, 1953). After this initial training period, responding was developed and maintained under two different schedules of reinforcement: a fixed ratio 50 schedule (FR 50) in which every 50th key peck response produced food and under a fixed interval (FI) 15-min schedule in which the first response after the passage of 15 min produced food. Two pigeons were trained initially under each schedule, and drug effects were determined. The pigeons were then switched to the other schedule, and again after the development of stable responding, the dosing was repeated. These two schedules generated different rates and patterns of responding with a mean rate of responding maintained by the FI schedule of 24 responses per minute and a mean rate of responding under the FR schedule of 104 responses per minute (Fig. 3). The FR schedules generated a very high, steady rate of responding that followed a brief pause after reinforcement, whereas the FI schedule engendered an acceleration in responding throughout the 15-min interval (i.e., the typical "scalloped" appearance) with a low response rate occurring in the initial portion of the interval followed by an increasing rate of responding until the first response after the 15-min period elapsed produced food. Five doses of pentobarbital were studied under each of the schedule conditions in all pigeons; the average dose-response curves are depicted in Fig. 4.

Perhaps the most striking aspect of these results was, as the title of the article indicates, the differential sensitivity to pentobarbital depending on the schedule of reinforcement. The lower doses of pentobarbital $(0.25$ and $0.5 \mathrm{mg})$ increased responding under both the FI and FR schedules, whereas the 1.0- and 2.0-mg doses markedly reduced responding under

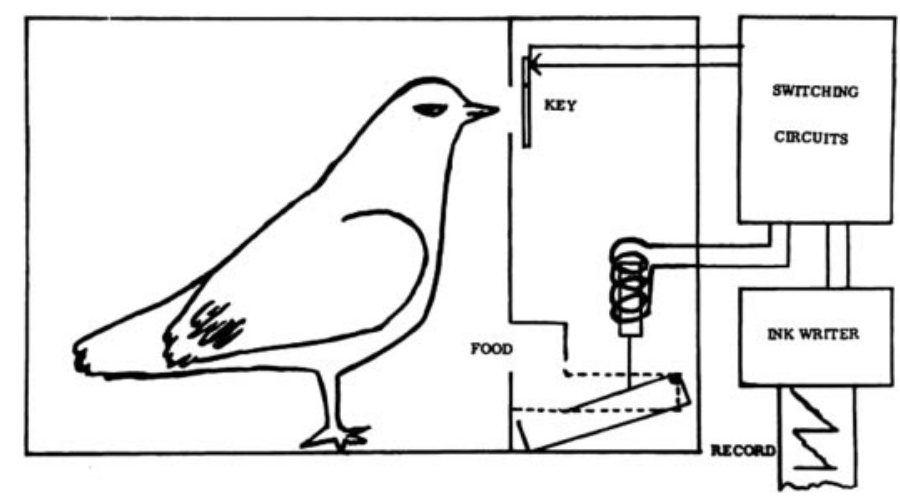

Fig. 2. Diagram of the apparatus used by Dews and others to study key-peck performances of pigeons. The Plexiglas key can be illuminated, and pecks on that key can produce mixed grain delivered from the food magazine. The switching circuits were used to control different schedules of reinforcement, and the ink writer was used to record behavioral performances (Dews, 1955a). 


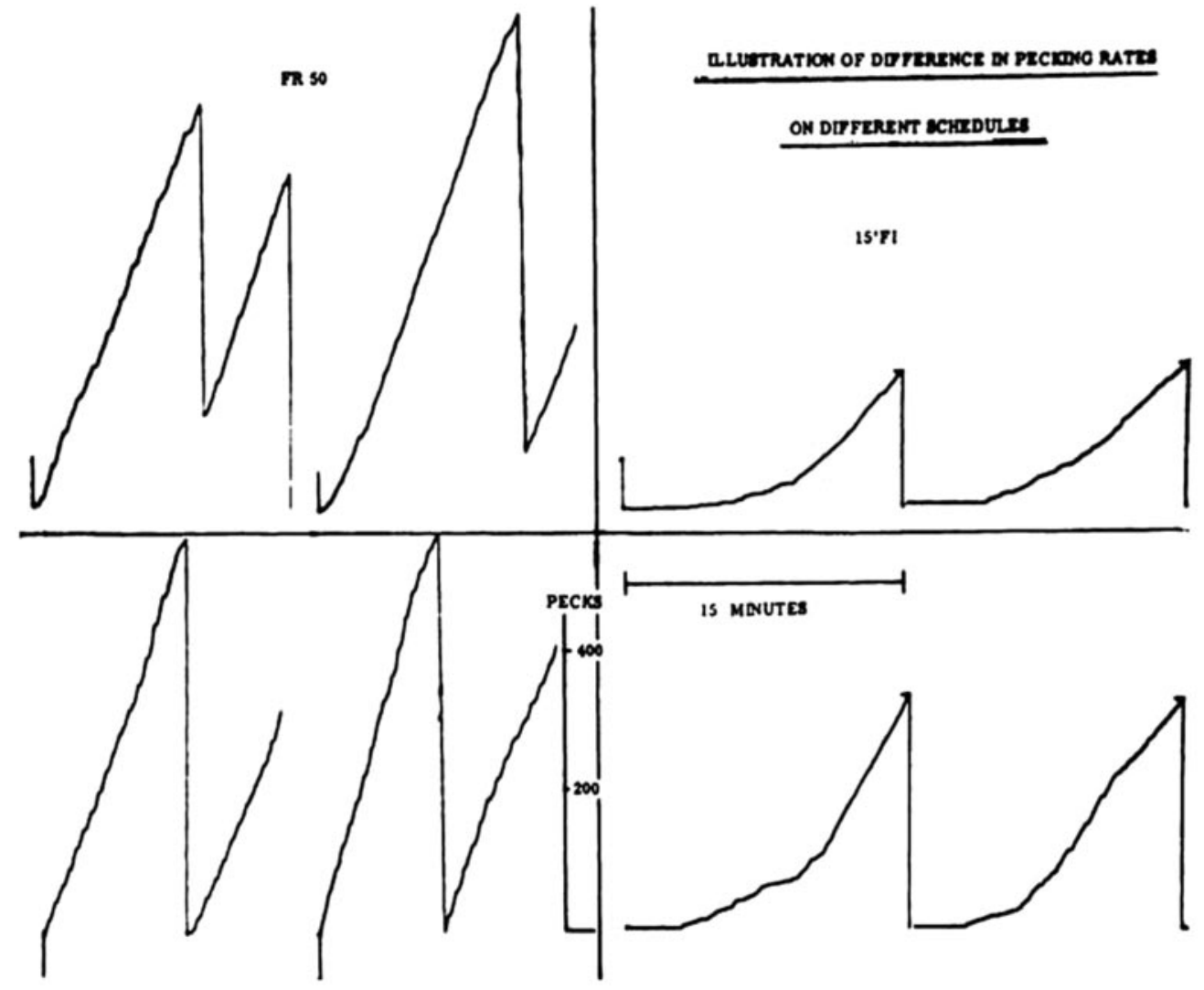

Fig. 3. Key pecking rates of pigeons under the FR 50 (left) and under the FI 15-min schedules (right). It is not possible to see the delivery of food under the FR schedule but note the high relatively steady rates maintained; slight pauses in the record can be seen, most likely following food delivery. The FI recording pen was reset to the baseline upon the delivery of food. Note the gradual, accelerating rate of responding and the curvature of the record showing the "scalloped" pattern of responding under the FI schedule (Dews, 1955a).

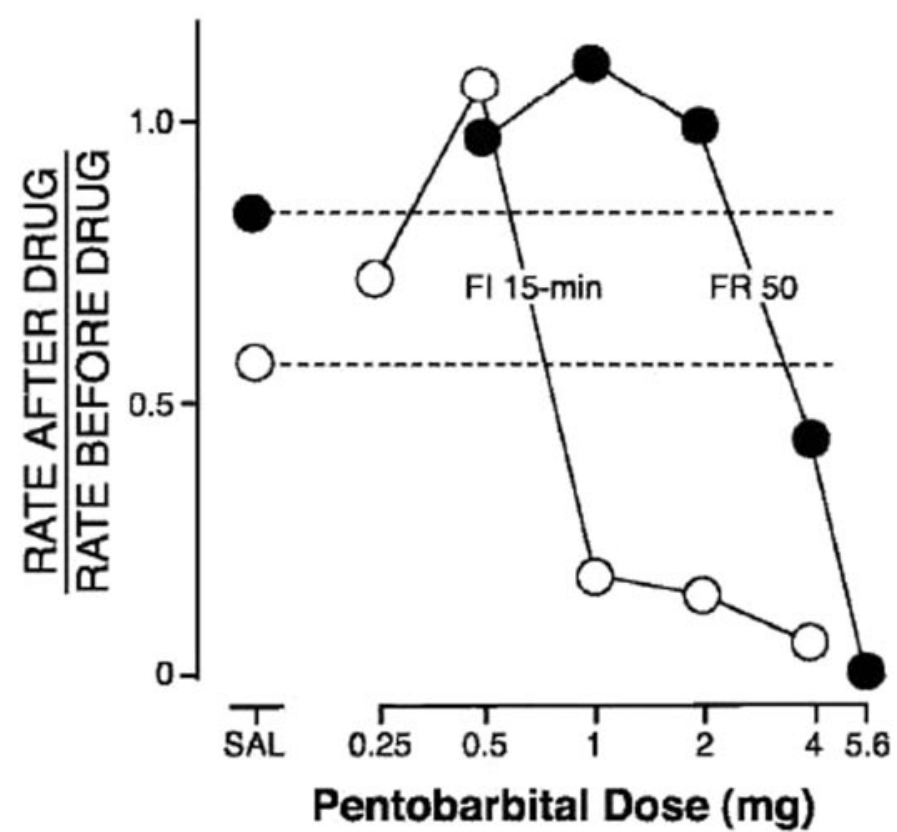

Fig. 4. Dose-response curves of the effects of pentobarbital under the FR and FI schedules of reinforcement. Note the increases in the high rates of responding under the FR schedule at doses of 1 and $2 \mathrm{mg}$ of pentobarbital; these same doses produced a marked reduction in responding under the FI schedule. Adapted from Dews (1955a) and reproduced with permission from Barrett (2006).

the FI schedule while still producing increases in responding maintained under the FR schedule. Thus, the same dose of pentobarbital both increased and decreased responding depending on the schedule of reinforcement, a finding demonstrating that the behavioral effects of drugs could not be easily understood independently of the schedule conditions under which they were studied. Moreover, although there was a reduction in responding under the FI schedule, this could not be attributed to an inability to respond because key pecking was actually increased under the FR schedule. Although the study involved different schedules of reinforcement and it was apparent that those schedule conditions determined the effects of pentobarbital, it has become clearer since these initial studies that the schedule of reinforcement is a reflection or "microcosm" of the environment or the context in which behavior has occurred; as such, it has been acknowledged broadly as a significant contributor to the manner in which behavior is affected by many different drugs.

Schedule-controlled behavior and its broader extrapolations as suggested above emerged from this study as an important determinant of drug action. Indeed, this was the first demonstration of a finding that was to be repeated often during the ensuing 50 years and which was to repeatedly reaffirm the exquisite sensitivity of behavior to its environmental consequences and, in turn, to the effects of drugs. In Dews' (1955a) original study, the pigeons were exposed to the two different schedules sequentially with those exposures occurring in different experimental sessions. Similar results have been demonstrated when pigeons were exposed to the two schedules under a multiple schedule procedure. Under this procedure, the two different schedules alternate within a single experimental session, and each schedule is associated with a distinctively different visual stimulus (see Fig. 10 in McKearney and Barrett, 1978; Barrett, 1980). Furthermore, under similar FR and FI schedules, $d$-amphetamine produces effects opposite those of pentobarbital, increasing responding 
under the FI schedule while, at the same dose, decreasing responding under the FR schedule (see Fig. 10 in McKearney and Barrett, 1978). Thus, the importance of the schedulecontrolled rate and pattern of responding is not limited to pentobarbital and would appear to have broad generality.

These early findings reported by Dews and elaborated subsequently by others demonstrated that, in the same animal and in rapid succession, drugs such as pentobarbital or amphetamine can produce either an "excitatory" or an "inhibitory" effect depending simply on the schedule controlling behavior. These results, demonstrating that the behavioral effects of drugs can be shown to rapidly oscillate from enhancement to depression depending simply on the control of behavior by external stimuli and the associated schedules of reinforcement, are difficult to explain purely from a mechanistic or pharmacological perspective. There have been attempts to evaluate the influence of schedules of reinforcement on neurochemical changes associated with schedule-controlled behavior (Lewy and Seiden, 1972; Seiden et al., 1975; Sparber, 1975; Miyauchi et al., 1988a,b; Barrett and Hoffmann, 1991), but very little progress has been made in this area that might permit a better understanding of the dynamic interactions between the behavioral and neurochemical processes that could shed further light on these early findings.

An often unacknowledged aspect of this study is that Dews also performed observational studies of the pigeons and the effects of pentobarbital by placing them into a large open glass jar and observing them throughout the duration of the drug effect. In these observational studies, there were no detectable effects of the 1.0-mg pentobarbital dose, whereas this dose produced significant modifications in the pecking behavior under the FI schedule, resulting in a substantial reduction in the rate of responding. As Dews pointed out, the use of the experimental techniques employed "permits the effect of a drug on a behavioral activity of an animal to be detected and measured following a dose insufficient to cause gross disturbance of the animal" (Dews, 1955a). Thus, the use of key peck performances maintained by schedules of reinforcement met a prerequisite that Dews had established for this study-the detection and measurement of a behavioral effect at doses of the drug that did not result in gross disturbances of behavior. In short, the first study in this series demonstrated the greater sensitivity of schedule-controlled behavior to the actions of pharmacological agents than simply gross behavioral observations. Furthermore, these results provided the first insight into the schedule- and response-dependent effects of drugs, a finding that was to be substantially elaborated in further studies (Kelleher and Morse, 1968).

\section{Studies on Behavior. I: Summary and Conclusions}

In the Discussion section of this initial article (Dews, 1955a), Dews suggests that the differential sensitivity to pentobarbital under the two different schedules of reinforcement might have been due to the control rate of responding. This theme was to recur in many different forms in subsequent publications and served as the basis for the "rate dependence hypothesis" that postulated that the behavioral effects of a drug were, under many conditions, inversely proportional to the control rate of responding (see also Dews, 1964; Kelleher and Morse, 1968; Dews and Wenger, 1977; McKearney and Barrett, 1978; McKearney,
1981). Indeed, it has been demonstrated repeatedly and under widely disparate conditions that the rate of responding in the absence of a drug can contribute significantly to the effects that drug will have on that behavior (Kelleher and Morse, 1964; MacPhail and Gollub, 1975; Dews, 1981; McKearney, 1981). Although there are conditions under which response rate in the absence of a drug does not appear to play an overwhelming role in determining the behavioral response when the drug is administered, e.g., with suppressed or punished responding (Dews and Wenger, 1977; but also see Spealman and Katz, 1980; McKearney, 1981), a principle need not be all encompassing to be of fundamental importance. Another interesting aspect of the initial paper in the series was the statement, as mentioned previously, that pentobarbital, typically characterized as a central nervous system-depressant, actually increased the average response rate, suggesting that this "might properly be considered a behavioral stimulating effect" (Dews, 1955a). In a subsequent commentary on this initial paper, published in Harvey (1971), Dews (1971) stated that this first study was an attempt to “. . . use schedule-dependent responding to measure effects of drugs. ... Other workers sought behavioral baselines for measurement of drug effects on emotions, motivations, cognitions, inhibitions, learning, and other hypothetical or arbitrarily defined constructs. A great many publications attest to the diligence of these attempts, although the accomplishments have been modest, to say the most. Effects reasonably attributable to changes in these hypothetical variables have been small and often not replicable either in other laboratories or even in the same laboratory under slightly different circumstances. One problem is that the behavior itself has constantly intruded as a determinant of the drug effects, obscuring the effects of the drugs on those processes of which the behavior was supposed to be merely an outward sign. Rates and patterns of responding have overshadowed motivation, putative emotions . . . as determinants of drug effects. . . It is the characteristics of the responding itself, particularly the temporal characteristics, that one should look first for determinants and substrates of drug effects on behavior. ... Schedules of reinforcement are pre-eminent influences on patterns of responding and thereby become pre-eminent independent variables in determining drug effects ... schedules are not the exclusive determinants of behavior nor of drug effects thereon; but they are ubiquitous as well as powerful, and their effects must always be taken into serious account, from the first, in the analysis of drug effects on behavior" (Dews, 1971).

This article, clearly provocative in its findings and impact on the prior dominance of hypothetical constructs as "explanations" of drug effects on behavior, as well as for charting the future of this discipline, was followed shortly by the second article of the series (Dews, 1955b). These two articles provide the main focus of this Centennial Perspective, with highlights and implications drawn from the remaining three articles.

\section{Studies on Behavior. II. The Effects of Pentobarbital, Methamphetamine, and Scopolamine on Performances in Pigeons Involving Discriminations}

As mentioned above, it has been possible to bring performances associated with various schedules under stimulus 
control where the different schedules are each associated with distinctive stimuli, such as differently colored key lights. In general, the behavioral performances and the pharmacological results under such multiple schedules are comparable with those observed when they are studied in isolation, although interactions between components of multiple schedules have been noted both behaviorally (Reynolds, 1961) and pharmacologically (Barrett and Stanley, 1980; Barrett et al., 1989). The second article in the series on Studies on Behavior examined the effects of pentobarbital, methamphetamine, and scopolamine on discriminative performances, again in pigeons (Dews, 1955b). The types of behavioral performances maintained in this study were several and consisted of combining different key light colors and house light combinations with a variable interval (VI) schedule of food delivery or with extinction, i.e., when key peck responses did not result in food delivery. The schedules used in this experiment differed in degrees of complexity, and different pigeons were used for each of the schedule conditions. Dews himself eschewed the use of the term "complexity" as well as that of "simple" because of the difficulty of defining them in this context. $\mathrm{He}$ wrote that "it would appear preferable to describe the differential sensitivity to drugs in terms of the operational differences between the schedules" (Dews, 1955b). To illustrate the variation in the types of discriminations that were established, one schedule condition consisted of a rather straightforward alternation throughout the session of different key light colors; key pecks in the presence of one color resulted in food delivery under the VI schedule, and key pecks in the presence of the alternate color had no consequence (extinction). A second form of discrimination was established in which the same color key light was used throughout the experimental session, but when the house light was illuminated, the extinction procedure was in effect. A more complex conditional discrimination procedure was also developed in which pecking produced food when a red key light was illuminated but did not produce food when the house light was also turned on. In the presence of a blue key light, pecking was not reinforced with food unless the house light was illuminated. Thus, the illumination of the house light signified food availability when the blue key light was illuminated but not when the key light color was red. Also in this same schedule condition, key pecking in the presence of a yellow key light was reinforced under the VI schedule, whereas key pecking in the presence of a white key light was not.

Figure 5A depicts the performance of pigeons under the schedule procedure when the red and blue key light colors alternated and key pecks during the red key light produced food. Excellent discriminative performances were established and maintained under this schedule with high rates of responding during the red key light where pecking produced food under the VI schedule and an almost complete absence of responding during the blue key light where key pecking was not reinforced. The effects of $3 \mathrm{mg}$ of pentobarbital are also shown in this figure and indicate that this dose of pentobarbital had little effect on these performances; that is, the discrimination remained intact following drug administration. Figure 5B depicts performances under the more complex conditional discrimination procedure. Here again, key pecking was nicely controlled in the absence of pentobarbital (left set of curves) despite the complexity of the discrimination schedule. Thus, for example, when the key was illumi- nated red $(\mathrm{R})$ and responding was reinforced, pecking occurred at a high steady rate, whereas when the key light was red and the house light illuminated $(\mathrm{R}+)$ and extinction was in effect, very low levels of responding were maintained.

Despite the overall similarities in the baseline (nondrug) performances under these two schedules, the effects of pentobarbital differed dramatically under the different discrimination procedures (Fig. 5, compare A with B). Under the conditional discrimination procedure (Fig. 5B), responding was markedly increased during the component when extinction was in effect (e.g., in the portion of the figure labeled $\mathrm{R}+$ ). Methamphetamine and scopolamine were also studied using these discrimination procedures, and methamphetamine, like pentobarbital, disrupted the schedule involving complex conditional discriminations, whereas scopolamine did not. Neither scopolamine nor methamphetamine had an effect on the strictly alternating performance depicted in Fig. $5 \mathrm{~A}$, as was the case with pentobarbital.

\section{Studies on Behavior. II: Summary and Conclusions}

The findings reported in the second article (Dews, 1955b) were as striking and compelling as those reported in the first article to appear in this series (Dews, 1955a), in that they demonstrated how sensitive behavior could be to drug effects when that behavior is differentially controlled by environmental consequences. In the initial article, using FR and FI schedules of reinforcement, the behavioral performances under these conditions were quite different in terms of their rate and patterning of responding, and these different performances were differentially sensitive to pentobarbital. In the second article (Dews, 1955b), the control performances were quite comparable under the different discriminative stimulus conditions, but the effects of pentobarbital and methamphetamine differed dramatically depending on the way in which that discrimination was maintained. The importance of these findings is that they illustrate that an evaluation of the effects of these drugs on discriminative performance requires a clear understanding of the manner in which behavior is controlled under various discriminative stimulus conditions (see Commentary by Dews in Harvey, 1971). Thus, with the first two articles, Dews (1955a,b) established that the schedule of reinforcement, which is the manner in which behavior is controlled by its consequences and by the discriminative context, is of critical importance to determining the effects that a drug will have on behavior. Subsequent studies by Dews (1964) with amobarbital, as well as by others such as Terrace (1963) and Laties and Weiss (1966), continued the experimental study of the effects of drugs on behavior controlled by discriminative stimuli, emphasizing variables such as the history of the animal in establishing the discrimination as well as the maintenance of behavior under various experimental conditions.

\section{Studies on Behavior. III-V.}

The remaining three articles in this series, all conducted with pigeons as experimental subjects, examined 1) the effects of scopolamine on discrimination performance (Studies on Behavior. III.) (Dews, 1957); 2) the stimulant effects of methamphetamine under various schedules of reinforcement that included FR 50 and 900, FI $15 \mathrm{~min}$, and VI $1 \mathrm{~min}$ (Studies on Behavior. IV.) (Dews, 1958); and 3) the actions of 

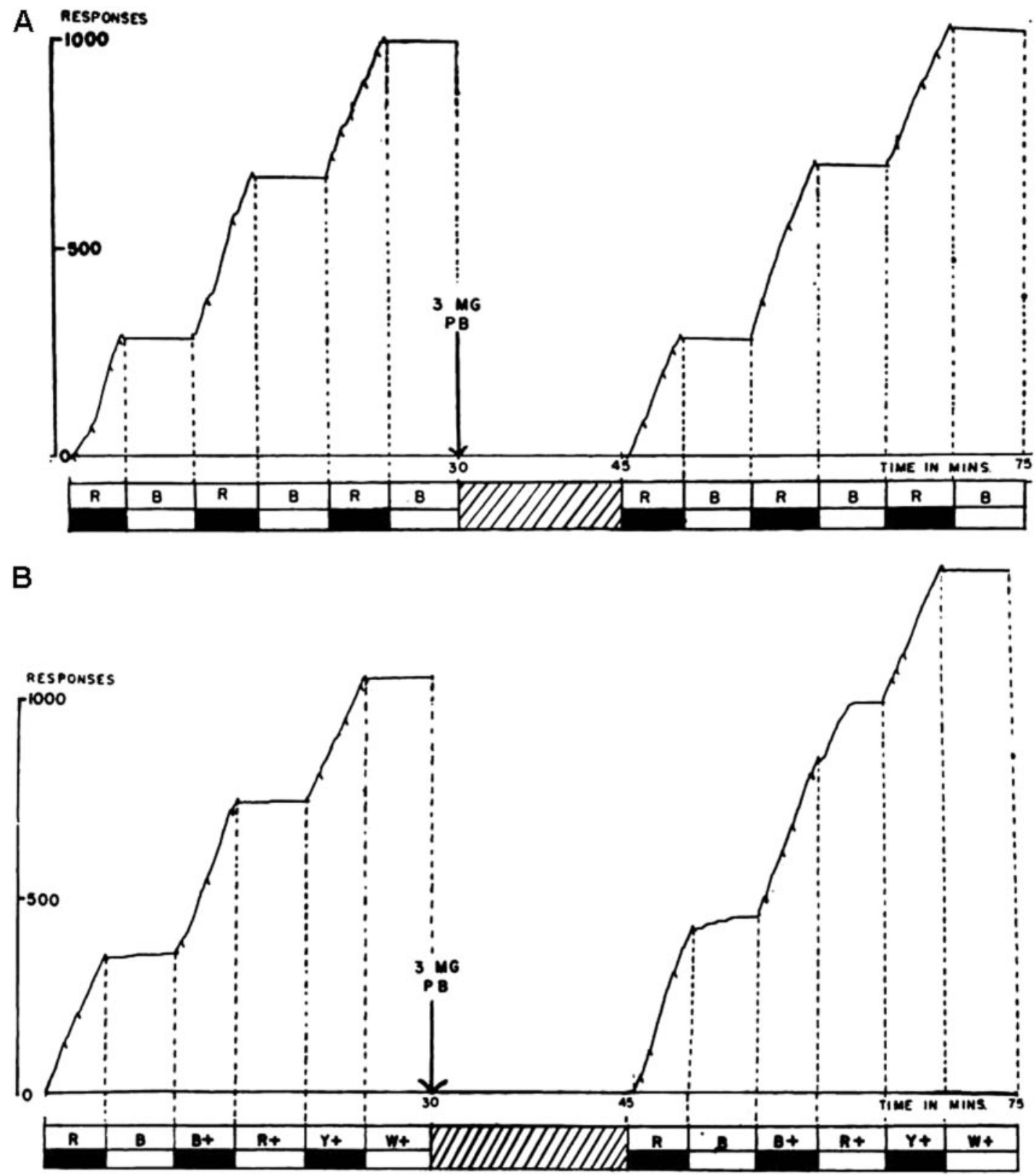

Fig. 5. A, effects of pentobarbital on performance under a multiple schedule in which responding during a red key light stimulus (R) produced food under a variable-interval schedule; when the key light was blue, no food was delivered. Steady rates of responding occurred when the key light was red, and responding did not occur when the key light was blue (extinction). The different key light periods are indicated below the records. The diagonal slashes on the records indicate food delivery. Pentobarbital administration ( $3 \mathrm{mg}$, indicated on the record) had little effect on performance under this schedule (Dews, 1955b). B, effects of pentobarbital on performance when there was a conditional discrimination in effect. The designations of the schedule conditions and the discrimination are indicated beneath the cumulative records. $R$, key light was red, and a variable-interval schedule was in effect; responding occurred as steady rates. B, the key light was illuminated blue, and extinction was in effect; B+, the key light was blue, and the house light was illuminated when the variable-interval schedule was in effect. $\mathrm{R}+$, with the red key light and the house light illuminated, extinction was in effect. $\mathrm{Y}+$, the variable interval schedule was operative during a yellow key light stimulus. W+, when the key light was white and the house light was illuminated, extinction was in effect. There was an almost complete absence of responding when key pecks did not produce food (B, $\mathrm{R}+$, and $\mathrm{W}+$ in the absence of the drug but note that the administration of pentobarbital (right-hand cumulative record) responding during the components when extinction was in effect. Pentobarbital had little effect on responding reinforced during the other components (Dews, 1955b).

$l$-epinephrine and related compounds using performances maintained under an FI 15-min schedule to examine whether the site of action of $l$-epinephrine was peripheral or centrally mediated (Studies on Behavior. V.) (Wurtman et al., 1959). In short, these three additional studies further demonstrated the utility and sensitivity of behavior maintained by schedules of reinforcement in assessing and influencing drug effects and added incrementally to the foundation established by the first two articles in the series (Dews, 1955a,b). Of particular interest in the article by Dews (1958) was the results with pentobarbital obtained under an FR 900 schedule compared with the results obtained in Dews (1955a,b) where he used an FR 50 schedule. In the initial study, lower doses of pentobarbital increased responding maintained under the FR 50 schedule, whereas in the later study in which responding was maintained under the FR 900 schedule, re- 
sponding was uniformly decreased at all doses of pentobarbital compared to control response rates. Thus, these studies pointed to the fact that it is not simply the type of schedule that contributes to the behavioral effects of a drug but the precise manner in which that schedule controls behavior, i.e., the rates and patterns of responding that are generated under those conditions. It is significant that, at this early stage in the formation of the field of behavioral pharmacology, Dews ended Studies on Behavior. III. with the following statement (Dews, 1957):

"Every effort has been made in this work to deal exclusively with operationally defined variables and to control as completely as possible the factors influencing the number of pecks made (the dependent variable of the study). These exacting requirements have the disadvantages that they severely restrict the numbers of animals able to be studied (only four pigeons were used in the present work) and also that only relatively small fragments of the behavioral repertoire of an animal can be studied at any one time. On the other hand, the great majority of pharmacological researches in other fields do meet these requirements, and it would seem that the pharmacology of behavior can become an acceptable branch of pharmacology only if it meets the scientific standards of the rest of pharmacology".

This statement is also perhaps best appreciated in another quote from Dews (1956): "The . . criticism . . . that the dependent variable, the rate of pecking, is only a tiny fragment of the total behavior of the animal ... seems to be quite invalid from the standpoint of basic research. We do not accuse the biochemists of triviality when they attempt to isolate a pure enzyme system, although any one such system is only a tiny fragment of the total biochemical machinery of the cell. A detailed analysis is a prerequisite of a worthwhile scientific synthesis".

With the publication of Studies on Behavior. III-V., Dews approached topics and themes of broad interest, such as stimulus control, learning and memory, and the means to study the direct and indirect actions of drugs affecting the central nervous system that were to set the course of research for some time to follow.

\section{General Implications and Conclusions}

The significance of these five articles has been substantial in placing behavioral pharmacology research on firm footing. There were other concomitant and very significant developments that helped to develop this field such as the publication by Ferster and Skinner (1957) and the creation of the Journal of the Experimental Analysis of Behavior in 1958. Other individuals such as J. V. Brady established laboratories at the University of Maryland and Walter Reed Army Institute of Research following his pioneering work on the conditioned emotional response (Barrett, 2008), and the contributions of Dews' colleagues at Harvard University (R. T. Kelleher and W. H. Morse) provided additional momentum that moved behavioral pharmacology forward as a rigorous scientific discipline (Barrett, 2002, 2006; Branch, 2006; Marr, 2006; Zeiler, 2006). It is noteworthy that the articles reviewed here are presented in the context of the Centennial, celebrating the formation of the American Society for Pharmacology and Experimental Therapeutics, within which this subdiscipline of pharmacology - behavioral pharmacology- was founded. The research conducted by Dews pointed compellingly and convincingly to the considerable influence the environment has on behavior and on how those factors, in turn, potently influence drug action. The themes elaborated in these studies, the importance of schedule-controlled rate of responding, the potentially "unseen" influence of discriminative stimuli that is only manifested when a drug is administered, and above all the importance of careful specification of the objective and quantifiable aspects of behavior have guided generations of researchers for the past 50 years. It is appropriate to appreciate the impact of these studies during this centennial year of ASPET.

\section{References}

Barrett JE (1980) Behavioral pharmacology: recent developments and new trends. Trends Pharmacol Sci 1:215-218.

Barrett JE (2002) The emergence of behavioral pharmacology. Mol Interv 2:470475 .

Barrett JE (2006) Behavioral determinants of drug action: the contributions of Peter B. Dews. J Exp Anal Behav 86:359-370.

Barrett JE (2008) Pioneers in behavioral pharmacology: a tribute to Joseph V. Brady. $J$ Exp Anal Behav, in press.

Barrett JE, Glowa JR, and Nader MA (1989) Behavioral and pharmacological history as determinants of tolerance- and sensitization-like phenomena in drug action, in Tolerance and Sensitization to Psychoactive Agents: An Interdisciplinary Approach (Emmett-Oglesby MS and Goudie AJ eds) pp 181-219, Humana Press, NJ.

Barrett JE and Hoffmann SM (1991) Neurochemical changes correlated with behav ior maintained under fixed-interval and fixed-ratio schedules of reinforcement. $J$ Exp Anal Behav 56:395-405.

Barrett JE and Stanley JA (1980) Effects of ethanol on multiple fixed-interva fixed-ratio schedule performances: dynamic interactions at different fixed-ratio values. J Exp Anal Behav 34:185-198.

Branch MN (2006) Roger T. Kelleher, behavior analyst. J Exp Anal Behav 86:371384

Dews PB (1955a) Studies on behavior. I. Differential sensitivity to pentobarbital of pecking performance in pigeons depending on the schedule of reward. J Pharmaco Exp Ther 113:393-401.

Dews PB (1955b) Studies on behavior. II. The effects of pentobarbital, methamphetamine and scopolamine on performances in pigeons involving discriminations. $J$ Pharmacol Exp Ther 115:380-389.

Dews PB (1956) Modification by drugs of performance on simple schedules of positive reinforcement. Ann NY Acad Sci 65:268-281.

Dews PB (1957) Studies on behavior. III. Effects of scopolamine on reversal of a discriminatory performance in pigeons. J Pharmacol Exp Ther 119:343-353.

Dews PB (1958) Studies on behavior. IV. Stimulant actions of methamphetamine. J Pharmacol Exp Ther 122:137-147.

Dews PB (1964) A behavioral effect of amobarbital. Naunyn Schmiedebergs Arch Exp Pathol Pharmakol 248:296-307.

Dews PB (1971) Commentary, in Behavioral Analysis of Drug Action: Research and Commentary (Harvey, JA ed) pp 37-43, Scott, Foresman, and Company, Glenview, IL

Dews PB (1981) History and present status of rate-dependency investigations, in Advances in Behavioral Pharmacology Vol. 3 (Thompson T and Dews PB eds) pp 111-118, Academic Press, New York.

Dews PB and Wenger GR (1977) Rate-dependency of the behavioral effects of amphetamine, in Advances in Behavioral Pharmacology Vol. 1 (Thompson T and Dews PB eds) pp 167-227, Academic Press, New York.

Ferster CB (1953) The use of the free operant in the analysis of behavior. Psycho Bull 50:263-274.

Ferster CB and Skinner BF (1957) Schedules of Reinforcement, Appleton-CenturyCrofts, New York.

Harvey JA (1971) Behavioral analysis of drug action: research and commentary. Scott, Foresman and Company, Glenview, IL.

Hill HE, Belleville RE, and Wikler (1954) A Anxiety reduction as a measure of the analgesic effectiveness of drugs. Science 120:153.

Kelleher RT and Morse WH (1964) Escape behavior and punished behavior. Fed Proc 23:808-817.

Kelleher RT and Morse WH (1968) Determinants of the specificity of the behavioral effects of drugs. Ergeb Physiol 60:1-56.

Laties VG and Weiss B (1966) Influence of drugs on behavior controlled by internal and external stimuli. $J$ Pharmacol Exp Ther 152:388-396.

Lattal KA (2002) A tribute to the Harvard pigeon lab 1948-1998. J Exp Anal Behav 77:301.

Lewy AJ and Seiden LS (1972) Operant behavior changes norepinephrine metabolism in rat brain. Science 175:454-456.

MacPhail RC and Gollub LR (1975) Separating the effects of response rate and reinforcement frequency in the rate-dependent effects of amphetamine and scopolamine on the schedule-controlled performance of rats and pigeons. J Pharmacol Exp Ther 194:332-342.

Marr MJ (2006) A major trio. J Exp Anal Behav 86:355-357.

McKearney JW (1981) Rate dependency: scope and limitations in the explanation and analysis of the behavioral effects of drugs, in Advances in Behavioral Phar macology, Vol. 3 (Thompson T and Dews PB eds) pp 91-109, Academic Press, New York. 
McKearney JW and Barrett JE (1978) Schedule-controlled behavior and the effects of drugs, in Contemporary research in behavioural pharmacology (Blackman DE and Sanger DJ eds) pp 1-68, Plenum Press, New York.

Miyauchi T, Dworkin SI, Co C, and Smith JE (1988a) Specific effects of punishment on amino acids turnover in discrete rat brain regions. Pharmacol Biochem Behav 31:523-531.

Miyauchi T, Dworkin SI, Co C, and Smith JE (1988b) Specific effects of punishment on biogenic monoamine turnover in discrete rat brain regions. Brain Res 454:40 50 .

Reynolds GS (1961) An analysis of interactions in a multiple schedule. $J$ Exp Anal Behav 4:107-117.

Seiden LS, MacPhail RC, and Oglesby MW (1975) Catecholamines and drugbehavior interactions. Fed Proc 34:1823-1831.

Skinner BF and Heron WT (1937) Psychol Rec 1:340-346.

Sparber SB (1975) Neurochemical changes associated with schedule-controlled behavior. Fed Proc 34:1802-1812.
Spealman RD and Katz JL (1980)) Some effects of clozapine on punished responding by mice and squirrel monkeys. J Pharmacol Exp Ther 212:435-440.

Terrace HS (1963) Errorless discrimination learning in the pigeon: Effects of chlorpromazine and imipramine. Science 140:318-319.

Wentink EA (1938) The effects of certain drugs and hormones upon conditioning. $J$ Exp Psychol 22:150-163.

Wurtman RJ, Frank MM, Morse WH, and Dews PB (1959) Studies on behavior. V. Actions of $l$-epinephrine and related compounds. J Pharmacol Exp Ther 127:281287

Zeiler MD (2006) An architect of the golden years. J Exp Anal Behav 86:385-391.

Address correspondence to: Dr. James E. Barrett, Department of Pharma cology and Physiology, Drexel University College of Medicine, 245 N. $15^{\text {th }}$ Street, Mail Stop 488, Room 8213, Philadelphia, PA 19102-1192. E-mail: jbarrett@drexelmed.edu 